\title{
An Approach to Solutions of Fractal and Fractional Time Derivative Fokker-Planck Equation
}

\author{
Hamdy Abdel-Gawad ${ }^{1}$ \\ ${ }^{1}$ Cairo University
}

May 5, 2020

\begin{abstract}
Abstract An approach to find the exact solution of ordinary, fractal and fractional Fokker-Planck equation FPE, based on transforming it to a system of first-order PDEs, together with using the extended unified method, is presented. Reduction of the fractal and fractional derivatives to the classical on's with time-dependent coefficient is performed via similarity transformations. Some explicit solutions of the classical, fractal and fractional time derivative FPE, are obtained. It is shown that the solution of the FPE is mixed Gaussian's. It is worthy to mention that the mixture of Gaussians is a powerful tool in machine learning. Further,it is found that the friction coefficient plays a significant role in lowering the magnitude of the distribution function. While changing the order of the fractal and fraction time derivative has a slight effects and the mean and mean square of the velocity vary slowly.
\end{abstract}

\section{Hosted file}

Fokker. last. lyx.pdf available at https://authorea.com/users/301074/articles/430853-anapproach-to-solutions-of-fractal-and-fractional-time-derivative-fokker-planck-equation
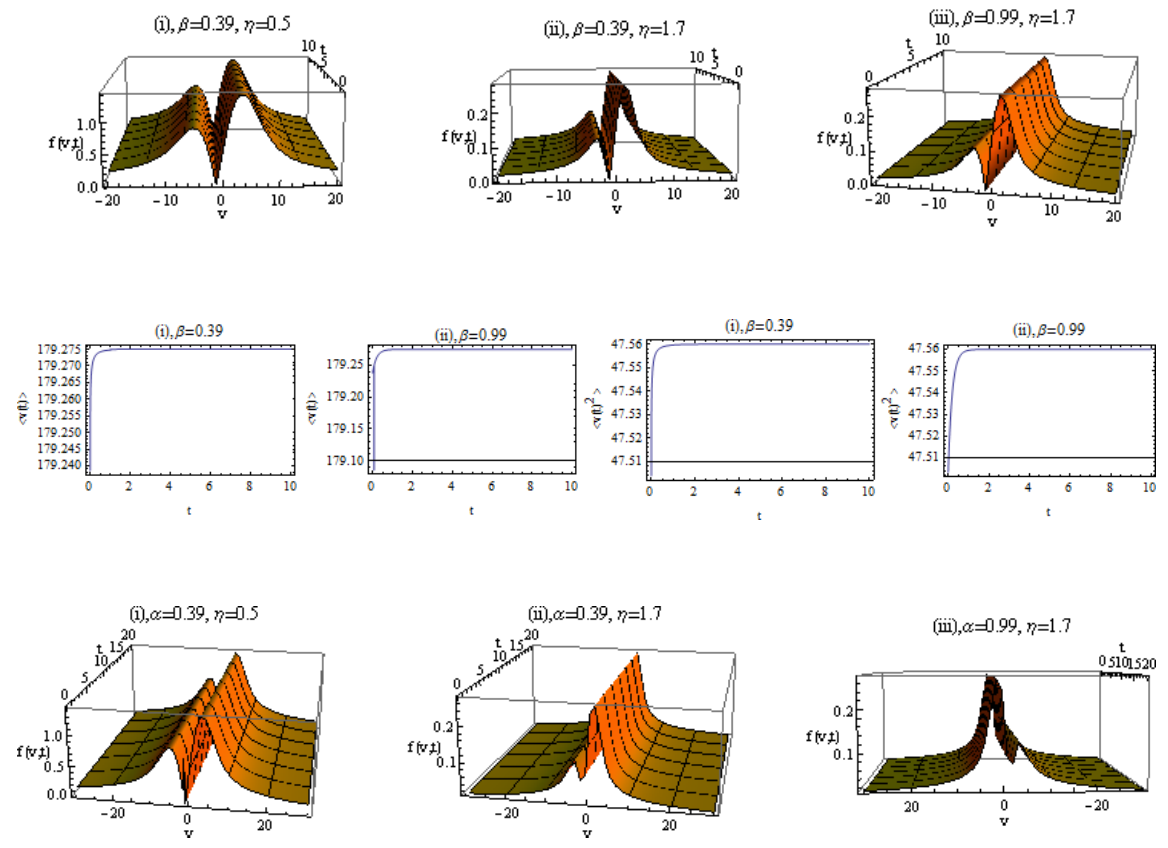

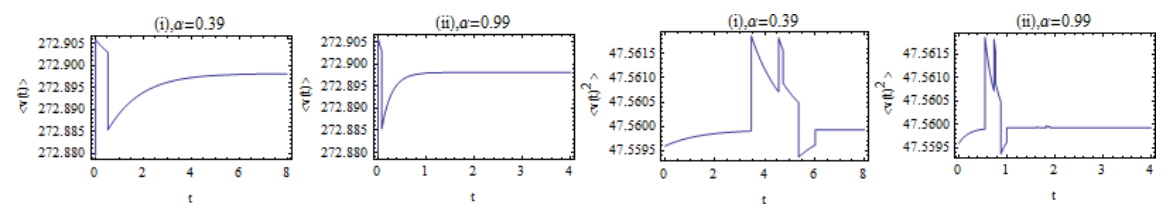